\title{
Disabling dyspnoea in patients with advanced disease: lack of effect of nebulized morphine
}

\author{
A. Noseda*, J.-P. Carpiaux*, C. Markstein**, A. Meyvaert+, V. de Maertelaer++
}

Disabling dyspnoea in patients with advanced disease: lack of effect of nebulized morphine. A. Noseda, J.-P. Carpiaux, C. Markstein, A. Meyvaert, V. de Maertelaer. CERS Journals Ltd 1997.

ABSTRACT: The purpose of this placebo-controlled, double-blind, randomized study was to assess the effect of nebulized morphine on dyspnoea perceived at rest by patients with advanced disease.

Seventeen hospital in-patients with disabling dyspnoea received isotonic saline or morphine via nebulization for $\mathbf{1 0}$ min through a mouthpiece, combined with oxygen via nasal prongs. On four consecutive days, they were given one of the four following treatments in random order: saline with $2 \mathrm{~L} \cdot \mathrm{min}^{-1}$ oxygen; $10 \mathrm{mg}$ morphine with $2 \mathrm{~L} \cdot \mathrm{min}^{-1}$ oxygen; $20 \mathrm{mg}$ morphine with $2 \mathrm{~L} \cdot \mathrm{min}^{-1}$ oxygen; and 10 mg morphine without oxygen (prongs fixed, no flow). Dyspnoea was assessed on a bipolar visual analogue scale (VAS) $(-100 \%$ much more short of breath, $+100 \%$ much less short of breath), and arterial oxygen saturation $\left(\mathrm{S}_{\mathrm{a}}, \mathrm{O}_{2}\right)$ and respiratory frequency $(f R)$ were recorded at the end of nebulization and $10 \mathrm{~min}$ later.

In 14 subjects who completed the study, mean VAS ratings 10 min after the end of nebulization ranged +30 to $+43 \%$, with no significant difference between the four study days (VAS $20 \mathrm{mg}$ morphine minus VAS saline, $95 \%$ confidence interval $(95 \% \mathrm{CI})-6$ to $+8 \%)$. $S \mathrm{a}, \mathrm{O}_{2}$ significantly increased on the 3 days with supplemental oxygen, and remained stable on the zero flow day. Respiratory frequency significantly decreased on the $\mathbf{4}$ days, with a trend to correlation between VAS rating and parallel change in respiratory frequency (Spearman's rank correlation coefficient $\left.\left(r_{s}\right)=-0.46 ; p=0.09\right)$.

We conclude that the subjects benefited from saline or morphine via a placebo effect and/or a nonspecific effect, and that nebulized morphine had no specific effect on dyspnoea.

Eur Respir J 1997; 10: 1079-1083.
*Dept of Medicine, Pulmonary Division, **Palliative Care Support Team and +Pharmacy, Hôpital Universitaire Brugmann, Brussels, Belgium, ${ }^{++}$Medical Statistical Unit, IRIBHN, Campus Erasme, Université Libre de Bruxelles, Brussels, Belgium.

Correspondence: A. Noseda

Dept of Medicine

Pulmonary Division

Hôpital Universitaire Brugmann

Place A. Van Gehuchten 4

B-1020 Brussels

Belgium

Keywords: Dyspnoea nebulized morphine visual analogue scale

Received: June 141996

Accepted after revision January 61997
Disabling dyspnoea associated with severe lung or heart disease is often inadequately controlled, even with maximal treatment of the underlying condition. Systemic treatment with opioids has been reported to reduce dyspnoea in some patients groups [1,2], but adverse effects are common and preclude their long-term use. Nebulized morphine is potentially attractive, since it is free of the adverse effects associated with systemic therapy and uncontrolled studies have suggested a beneficial effect on dyspnoea [3, 4].

The present study tested the hypothesis that opioidsensitive receptors located in the respiratory tract [5] modulate dyspnoea perceived at rest by patients with advanced lung or heart disease. Hospital in-patients with disabling dyspnoea were, in a double-blind randomized protocol, given nebulized isotonic saline or nebulized morphine (10 or $20 \mathrm{mg}$ ) and the change in perceived shortness of breath was recorded on a bipolar visual analogue scale (VAS).

\section{Subjects and methods}

\section{Study design}

On four consecutive days, each subject received the four following treatments in random order: nebulized isotonic saline with oxygen; $10 \mathrm{mg}$ nebulized morphine with oxygen; $20 \mathrm{mg}$ nebulized morphine with oxygen; and $10 \mathrm{mg}$ nebulized morphine without oxygen. The primary outcome variable was dyspnoea, rated on a bipolar VAS; additional variables were arterial oxygen saturation $\left(\mathrm{Sa}_{\mathrm{a}} \mathrm{O}_{2}\right)$ and respiratory frequency $(f \mathrm{R})$. The protocol was approved by the Ethics Committee of the Hôpital Brugmann, and each subject gave informed consent.

\section{Subjects}

All subjects were hospital in-patients with severe lung or heart disease. Criteria for entry into the study were: 1) distressing dyspnoea not relieved by conventional medical therapy, (i.e. maximal treatment of underlying pulmonary and/or cardiac disease, including management of pleural effusion, when present); and 2) ability to rate dyspnoea on a VAS, as judged from normal cognitive function (Mini-Mental State Questionnaire Score of at least 24/30) [6], and specific understanding of the scale used in this study.

Seventeen patients ( 13 males and 4 females) were studied. Their anthropometric and clinical features are presented in table 1 . The most frequent diagnosis (12 subjects) was chronic obstructive pulmonary disease (COPD); 
Table 1. - Anthropometric and clinical features of 17 patients with advanced disease and disabling dyspnoea

\begin{tabular}{|c|c|c|c|c|c|c|c|c|}
\hline $\begin{array}{l}\mathrm{Pt} \\
\text { No. }\end{array}$ & Sex & $\begin{array}{l}\text { Age } \\
\text { yrs }\end{array}$ & $\begin{array}{l}\text { Height } \\
\mathrm{cm}\end{array}$ & $\begin{array}{l}\text { Weight } \\
\mathrm{kg}\end{array}$ & $\begin{array}{c}\text { Main } \\
\text { diagnosis }^{\#}\end{array}$ & $\begin{array}{l}\text { Additional } \\
\text { diagnosis }\end{array}$ & $\begin{array}{l}\mathrm{VC} \\
\mathrm{L}\end{array}$ & $\begin{array}{c}\text { FEV1 } \\
\text { L }\end{array}$ \\
\hline 1 & M & 70 & 163 & 63 & COPD & \multirow{8}{*}{$\begin{array}{l}\text { Talc pleurodesis } \\
\text { Anaemia }\end{array}$} & 1.91 & 0.73 \\
\hline 2 & M & 86 & 160 & 53 & COPD & & 2.56 & 1.15 \\
\hline 3 & $\mathrm{~F}$ & 53 & 152 & 40 & COPD & & 1.70 & 0.74 \\
\hline 4 & M & 74 & 174 & 57 & COPD & & 1.69 & 1.07 \\
\hline 5 & $\mathrm{~F}$ & 67 & 153 & 65 & COPD & & 1.23 & 0.70 \\
\hline 6 & $\mathrm{M}$ & 78 & 160 & 50 & COPD & & 2.37 & 0.71 \\
\hline 7 & $\mathrm{~F}$ & 68 & 146 & 67 & COPD & & 1.94 & 0.74 \\
\hline 8 & $\mathrm{~F}$ & 74 & 146 & 50 & IPF & & 1.57 & 1.13 \\
\hline 9 & M & 59 & 170 & 86 & COPD & \multirow[t]{2}{*}{ Heart failure } & 3.08 & 1.08 \\
\hline 10 & M & 74 & 175 & 85 & COPD & & 2.92 & 1.64 \\
\hline 11 & M & 76 & 167 & 48 & Malignancy & \multirow[t]{3}{*}{ Left pneumonectomy } & 0.89 & 0.70 \\
\hline 12 & $\mathrm{M}$ & 58 & 169 & 53 & COPD & & 2.50 & 0.73 \\
\hline 13 & M & 84 & 169 & 60 & Heart failure & & NA & NA \\
\hline 14 & M & 44 & 178 & 68 & Malignancy & \multirow{4}{*}{$\begin{array}{c}\text { Talc pleurodesis } \\
\text { Heart failure }\end{array}$} & NA & NA \\
\hline 15 & M & 62 & 177 & 70 & Malignancy & & NA & NA \\
\hline 16 & M & 73 & 165 & 70 & COPD & & 1.63 & 0.70 \\
\hline 17 & M & 67 & 168 & 40 & COPD & & 2.93 & 1.02 \\
\hline \multirow{2}{*}{\multicolumn{2}{|c|}{$\begin{array}{l}\text { Mean } \\
\text { SD }\end{array}$}} & 69 & 164 & 60 & & & 2.07 & 0.92 \\
\hline & & 11 & 10 & 14 & & & 0.67 & 0.18 \\
\hline
\end{tabular}

\#: Main diagnosis responsible for dyspnoea; $\$$ : additional diagnosis likely to contribute to dyspnoea. Pt: patient; M: male; F: female; VC: vital capacity; FEV1: forced expiratory volume in one second; COPD: chronic obstructive pulmonary disease; IPF: idiopathic pulmonary fibrosis; NA: not available.

one of these patients had undergone talc pleurodesis for recurrent pneumothoraces. Of three subjects with malignancy as main diagnosis, one had recurrence of lung cancer on a stump of left pneumonectomy; one had lung cancer with pleural involvement; and one had metastatic pleurisy from unknown primary tumour. The latter two subjects had been managed by tube drainage and talc pleurodesis.

Spirometric data were available in 14 subjects and were consistent with severe airflow limitation. The treatments most often prescribed were: inhaled bronchodilators $(\mathrm{n}=14)$; oral or i.v. steroids $(\mathrm{n}=11)$; oral or i.v. theophylline $(n=9)$, diuretics $(n=8)$; nitrates $(n=8)$; and oxygen $(n=8)$. Steroids were given as a part of therapy for COPD, but also, although less frequently, for adrenal insufficiency $(n=1)$, perimetastatic cerebral oedema $(n=1)$, or hypercalcaemia $(n=1)$. Other treatments included: anticoagulants $(n=5)$; benzodiazepines $(n=5)$; inhaled steroids $(n=4)$; digoxine $(n=4)$; antibiotics $(n=4)$; antidepressants $(\mathrm{n}=2)$; analgesics $(\mathrm{n}=2)$; and angiotensin converting enzyme (ACE) inhibitor $(n=1)$.

\section{Treatment under investigation}

At time zero, the subject was asked to rest in bed. Oxygen was stopped in those subjects receiving oxygen as a part of in-hospital treatment. At time $15 \mathrm{~min}$, a $4 \mathrm{~mL}$ volume was nebulized, using an air-driven 5 $\mathrm{L} \cdot \mathrm{min}^{-1}$ flow rate for $10 \mathrm{~min}$, and administered to the subject via a mouthpiece. The solution contained either $10 \mathrm{mg}$ morphine chlorhydrate ( 2 of the 4 days), $20 \mathrm{mg}$ morphine chlorhydrate (1 day), or isotonic saline (1 day). Morphine solutions were stabilized using $1 \mathrm{mg}$ $\mathrm{Na}_{2} \mathrm{~S}_{2} \mathrm{O}_{5}$. All solutions were sterile and conserved at $4^{\circ} \mathrm{C}$, light-free. All morphine and saline solutions were prepared and coded independently in the hospital pharmacy. Oxygen was delivered at $2 \mathrm{~L} \cdot \mathrm{min}^{-1}$ via nasal prongs on 3 of the 4 days, including the $20 \mathrm{mg}$ morphine and the saline day. On one of the two $10 \mathrm{mg}$ days, prongs were fixed but no oxygen was given.

\section{Outcome variables}

Dyspnoea was rated on a $40 \mathrm{~cm}$ horizontal bipolar VAS labelled "much more short of breath" at the left end, "much less short of breath" at the right end and "no change" in the middle [7]. This scale allows the subject to report either an increase or a decrease in shortness of breath when moving off from the no change midpoint. It is particularly suited for evaluating the response to an acute intervention, and has been validated by our group in patients with chronic respiratory disease [7]. Dyspnoea ratings measured in this way are reported as percentages (range -100 to $+100 \%$ ).

Oxygen saturation was monitored using a Biox Ohmeda 3700 pulse oximeter (Madison, USA), with an ear probe. Respiratory rate was measured twice for $1 \mathrm{~min}$, and the two results were averaged. $S \mathrm{a}, \mathrm{O}_{2}$ and $f \mathrm{R}$ were measured at times $15 \mathrm{~min}$ (baseline), $25 \mathrm{~min}$ (end of nebulization), and $35 \mathrm{~min}$. VAS ratings were recorded at times $25 \mathrm{~min}$ and $35 \mathrm{~min}$.

\section{Statistical analysis}

Data were submitted to an analysis of variance (ANOVA) with two repeated measures: one for the treatments (four levels), and one for the time (two or three levels). In the case of significant difference between the treatments, mean contrasts between them were calculated. The study was designed to give a $90 \%$ chance of detecting a $25 \%$ change in dyspnoea at the $0.05 \mathrm{p}$ level. Assuming that dyspnoea could be assessed on the bi-polar VAS with a within-subject coefficient of variation of $15 \%$ [7], the sample size estimation indicated that at least 13 subjects were required. A p-value of less than 0.05 was considered statistically significant. 
Table 2. - Outcome variables (VAS, $\mathrm{Sa}, \mathrm{O}_{2}$ and $f \mathrm{R}$ ) for the 14 subjects who completed the study

\begin{tabular}{|c|c|c|c|c|c|c|c|c|c|c|c|c|}
\hline & \multicolumn{3}{|c|}{ Saline $+\mathrm{O}_{2}$} & \multicolumn{3}{|c|}{$10 \mathrm{mg}$ morphine $+\mathrm{O}_{2}$} & \multicolumn{3}{|c|}{$20 \mathrm{mg}$ morphine $+\mathrm{O}_{2}$} & \multicolumn{3}{|c|}{$\begin{array}{l}10 \text { mg morphine } \\
\text { without } \mathrm{O}_{2}\end{array}$} \\
\hline & $\begin{array}{c}15 \\
\min \end{array}$ & $\begin{array}{l}25 \\
\min \end{array}$ & $\begin{array}{c}35 \\
\min \end{array}$ & $\begin{array}{c}15 \\
\min \end{array}$ & $\begin{array}{l}25 \\
\min \end{array}$ & $\begin{array}{c}35 \\
\min \end{array}$ & $\begin{array}{l}15 \\
\min \end{array}$ & $\begin{array}{l}25 \\
\min \end{array}$ & $\begin{array}{c}35 \\
\min \end{array}$ & $\begin{array}{c}15 \\
\min \end{array}$ & $\begin{array}{l}25 \\
\min \end{array}$ & $\begin{array}{c}35 \\
\min \end{array}$ \\
\hline VAS rating \% & - & $\begin{array}{l}+34 \\
(25)\end{array}$ & $\begin{array}{l}+42 \\
(27)\end{array}$ & - & $\begin{array}{l}+23 \\
(24)\end{array}$ & $\begin{array}{l}+33 \\
(28)\end{array}$ & - & $\begin{array}{l}+31 \\
(26)\end{array}$ & $\begin{array}{l}+43 \\
(27)\end{array}$ & - & $\begin{array}{l}+26 \\
(30)\end{array}$ & $\begin{array}{l}+30 \\
(25)\end{array}$ \\
\hline $\mathrm{Sa}_{\mathrm{a}, \mathrm{O}_{2}} \%$ & $\begin{array}{l}93 \\
(5)\end{array}$ & $\begin{array}{l}95 \\
(5)\end{array}$ & $\begin{array}{l}95 \\
(4)\end{array}$ & $\begin{array}{l}91 \\
(7)\end{array}$ & $\begin{array}{l}93 \\
(7)\end{array}$ & $\begin{array}{l}93 \\
(6)\end{array}$ & $\begin{array}{l}90 \\
(4)\end{array}$ & $\begin{array}{l}93 \\
(4)\end{array}$ & $\begin{array}{l}94 \\
(4)\end{array}$ & $\begin{array}{l}91 \\
(5)\end{array}$ & $\begin{array}{l}90 \\
(8)\end{array}$ & $\begin{array}{l}90 \\
(8)\end{array}$ \\
\hline$f_{\mathrm{R}}$ breaths $\cdot \mathrm{min}^{-1}$ & $\begin{array}{l}20.1 \\
(4.0)\end{array}$ & $\begin{array}{l}17.0 \\
(3.7)\end{array}$ & $\begin{array}{l}19.1 \\
(3.9)\end{array}$ & $\begin{array}{l}19.8 \\
(5.6)\end{array}$ & $\begin{array}{l}18.7 \\
(5.3)\end{array}$ & $\begin{array}{l}17.9 \\
(5.3)\end{array}$ & $\begin{array}{l}20.3 \\
(3.8)\end{array}$ & $\begin{array}{l}18.4 \\
(4.2)\end{array}$ & $\begin{array}{l}19.1 \\
(4.6)\end{array}$ & $\begin{array}{l}19.9 \\
(4.1)\end{array}$ & $\begin{array}{l}17.5 \\
(3.7)\end{array}$ & $\begin{array}{l}19.0 \\
(3.9)\end{array}$ \\
\hline
\end{tabular}

Values are presented as mean, and $\mathrm{SD}$ in parenthesis. VAS: visual analogue scale; $\mathrm{Sa}_{\mathrm{a}} \mathrm{O}_{2}$ : arterial oxygen saturation; $f \mathrm{R}$ : respiratory frequency. $15 \mathrm{~min}$ : baseline; $25 \mathrm{~min}$ : at the end of nebulization; $35 \mathrm{~min}$ : $10 \mathrm{~min}$ after the end of nebulization.

\section{Results}

Fourteen of the 17 subjects completed the study. Subjects Nos. 6, 11 and 14 died (one with COPD, two with malignancy) on the third or fourth study day; all three deaths occurred during the night, none being related to the present experiment. The results that follow involve the 14 subjects who completed the study.

Of the 112 VAS ratings recorded throughout the study, 101 were positive (subject less short of breath), 7 zero (no change), and 4 negative (subject more short of breath). The 11 ratings $\leq 0 \%$ were obtained after either $10 \mathrm{mg}$ morphine with $(\mathrm{n}=4)$ or without $(\mathrm{n}=5)$ oxygen, or $20 \mathrm{mg}$ morphine $(\mathrm{n}=2)$. No rating $\leq 0 \%$ was recorded after saline. As shown in table 2, mean VAS ratings at time $25 \mathrm{~min}$ (at the end of nebulization) ranged from +23 to $+34 \%$. The additional improvement recorded at time $35 \mathrm{~min}$ (10 min after the end of nebulization) was significant $(\mathrm{p}=0.011)$. VAS ratings recorded at time 35 min are shown in figure 1 . No significant difference in effectiveness was detected between the four treatments under investigation $(\mathrm{p}=0.362)$. The $95 \%$ confidence interval $(95 \% \mathrm{CI})$ for the difference in VAS rating between the $20 \mathrm{mg}$ morphine day and the saline day was -12 to $+6 \%$ at time $25 \mathrm{~min}$, and -6 to $+8 \%$ at time $35 \mathrm{~min}$.
Mean baseline $\mathrm{Sa}_{\mathrm{a}} \mathrm{O}_{2}$ ranged $90-93 \%$ across the four study days (table 2). As expected, oxygen administration significantly increased $\mathrm{Sa}, \mathrm{O}_{2}$ when combined either with saline $(p<0.001), 10 \mathrm{mg}(p=0.002)$, or $20 \mathrm{mg}$ morphine $(\mathrm{p}<0.001)$. After $10 \mathrm{mg}$ nebulized morphine without supplemental oxygen, $\mathrm{Sa}_{\mathrm{a}} \mathrm{O}_{2}$ decreased slightly from 91 (5) to 90 (8) \%, but the decrease did not reach significance $(\mathrm{p}=0.216)$. At baseline, the subjects were mildly tachypnoeic at rest (mean $f \mathrm{R}$ 19.8-20.3 breaths $\left.\cdot \min ^{-1}\right)$. Respiratory frequency significantly decreased over time $(p=0.043)$, and no significant difference was detected between the four treatments ( $\mathrm{p}=0.861)$. As illustrated in figure 2, there was a tendency for the largest improvements in shortness of breath (at time 35 $\mathrm{min}$ ) to be associated with the largest decreases in $f \mathrm{R}$. The correlation between the two variables approached significance (Spearman's rank correlation coefficient $\left.\left(\mathrm{r}_{\mathrm{s}}\right)=-0.46 ; \mathrm{p}=0.09\right)$.

None of the treatments caused any important adverse effect. Four of the 56 experiments were associated with minor manifestations: one subject felt the nebulized solution pricked his throat on the $20 \mathrm{mg}$ morphine day and on the saline day; one subject complained about a bitter taste after $20 \mathrm{mg}$ morphine; and a burst of cough was observed following $20 \mathrm{mg}$ morphine in another subject.

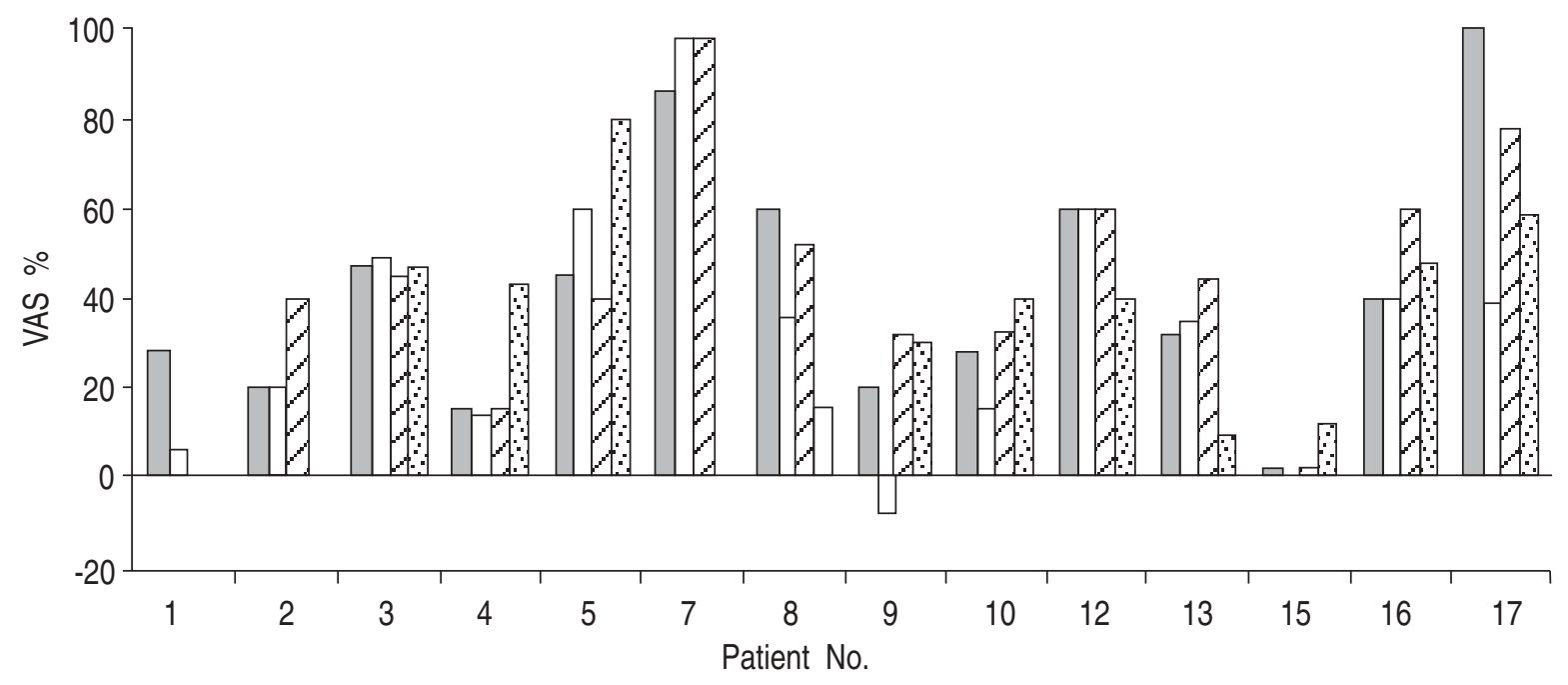

Fig. 1. - Visual analogue scale (VAS) ratings, expressed as a percentage, recorded, at time 35 min, on four consecutive days in 14 patients with disabling dyspnoea, $10 \mathrm{~min}$ after the end of: nebulized saline with $2 \mathrm{~L} \cdot \mathrm{min}^{-1}$ oxygen ( < -); $10 \mathrm{mg}$ morphine with $2 \mathrm{~L} \cdot \mathrm{min}^{-1}$ oxygen ( $)$; $20 \mathrm{mg}$ morphine with $2 \mathrm{~L} \cdot \mathrm{min}^{-1}$ oxygen ( ); or $10 \mathrm{mg}$ morphine without oxygen ( ). 


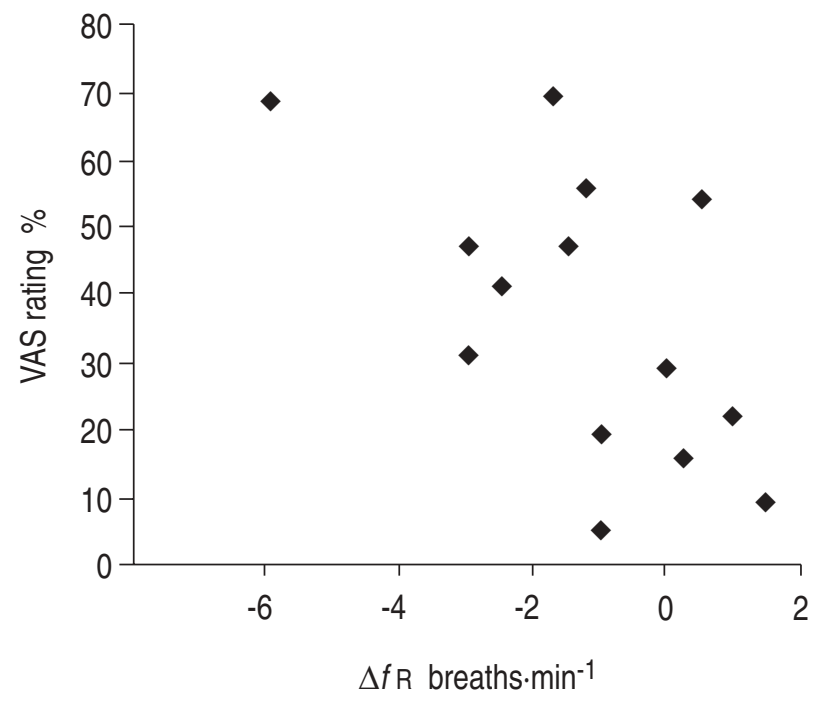

Fig. 2. - Visual analogue scale (VAS) ratings recorded at time 35 min, $10 \mathrm{~min}$ after the end of nebulized treatment plotted against the parallel changes in respiratory frequency $(\Delta f \mathrm{R})$. The values taken into account were the averages of the four treatments, since no treatment difference was detected either for VAS or $f$ R. A nonparametric correlation analysis was performed (Spearman's rank correlation coefficient $\left.\left(\mathrm{r}_{\mathrm{s}}\right)=-0.46 ; \mathrm{p}=0.09\right)$.

\section{Discussion}

In this controlled study, we assessed the effect of nebulized morphine on the sensation of dyspnoea experienced by hospital in-patients with advanced disease, and found no difference in efficacy between saline, and 10 $\mathrm{mg}$ or $20 \mathrm{mg}$ morphine. The study was originally designed because of recent claims that inhaled opioids are able to relieve severe dyspnoea from malignant or nonmalignant lung disease $[3,4]$. Our results do not support the hypothesis that nebulized morphine may decrease dyspnoea through a local action on the airways.

In two studies published in the 1980s, a decrease in exercise-induced dyspnoea was obtained in COPD subjects following oral administration of either $15 \mathrm{mg}$ dihydrocodeine [1], or $0.8 \mathrm{mg} \cdot \mathrm{kg}^{-1}$ of a morphine solution [2]. However, serious side-effects occurred in the latter study. Since the existence of opioid-sensitive receptors in the respiratory tract has been demonstrated [5], it is not surprising that the potential of inhaled morphine for reducing dyspnoea has elicited several trials. In 1989, Young et al. [8] reported an increase in exercise endurance in COPD patients after a low $5 \mathrm{mg}$ dose of nebulized morphine [8]. However, these authors did not assess dyspnoea, and their results were strongly influenced by a spectacular improvement in one individual. A first claim of a beneficial effect on dyspnoea at rest from a small $5 \mathrm{mg}$ dose of nebulized morphine involved a single patient with mesothelioma, whose dyspnoea was unresponsive to a large $160 \mathrm{mg} \cdot$ day $^{-1}$ oral dose of morphine [3]. In 1994, FARNCOMBE et al. [4] reported a beneficial effect in a group of 54 patients with disabling dyspnoea from either malignant $(n=40)$ or nonmalignant $(n=14)$ disease. Thirty four patients received morphine $(5-30 \mathrm{mg})$, the remainder various other opioids, and 34 of the 54 subjects claimed a decrease in shortness of breath. Although the study was uncontrolled and dyspnoea not quantitated, other groups com- mented with some enthusiasm about the results on the basis of a similar favourable experience with inhaled morphine $[9,10]$. The present study was specifically designed to evaluate the contribution of morphine-sensitive receptors located in the respiratory tract to the sensation of dyspnoea. Isotonic saline was used as placebo, and it was found that dyspnoea, quantitated on a bipolar VAS particularly well-suited to assess the response to an acute intervention, was not reduced to a greater extent following morphine than following saline.

The significance of this negative study needs to be discussed. That the dose of nebulized morphine was too small seems an unlikely explanation for the lack of specific effect on dyspnoea, since the 10 and $20 \mathrm{mg}$ doses used compare well with the 5-30 mg claimed to be beneficial in about two thirds of the subjects in the study by FARNCOMBE et al. [4]. That the delay to assess the response was not sufficiently long is no more convincing. Indeed, the mean delay to obtain a peak serum concentration following nebulized morphine is $45 \mathrm{~min}$ [11], so that we deliberately chose to record the response on the bipolar VAS after 10 and $20 \mathrm{~min}$, as the study aimed to specifically evaluate the intrapulmonary action of nebulized morphine. That the scale used to assess a change in shortness of breath was not sufficiently sensitive also seems unlikely, since this scale was shown to be sensitive to either bronchodilation [12] or to bronchoconstriction [13] in patients with asthma or COPD. Finally, the small number of patients (estimated for a size effect of $25 \%$ ) could be incriminated, but the difficulty of recruiting patients for this kind of study is obvious. Other groups have reported negative results with inhaled morphine. BEAUFORD et al. [14] found no effect of 1 to $10 \mathrm{mg}$ nebulized morphine on dyspnoea assessed during an incremental exercise test in COPD patients. Similarly, MASOOD and co-workers $[15,16]$ reported that the dyspnoea/ventilation relationship during submaximal exercise is unaffected by nebulized morphine (10 or $25 \mathrm{mg}$ ) either in healthy subjects [15] or in patients with COPD [16]. HARRIS-EzE et al. [17] reached the same conclusion in patients with interstitial lung disease, for smaller 2.5 and $5 \mathrm{mg}$ doses.

Whilst we were unable to demonstrate any specific effect from nebulized morphine on dyspnoea, the present study showed a beneficial effect on dyspnoea from the four regimens being evaluated. Indeed, 101 of the 112 VAS ratings recorded during the study were positive, meaning the subjects felt less short of breath than at baseline, and the increase in rating over time was statistically significant. Oxygen via nasal prongs was included in the study protocol, as there is a theoretical potential for inhaled morphine to lower oxygen saturation. Although the effect of supplemental oxygen on dyspnoea at rest has been disputed [18], at least two studies have shown that oxygen reduces dyspnoea at rest to a greater extent than air (delivered in similar fashion) in hypoxaemic patients with COPD [19], or with terminal cancer [20]. In the present study, the beneficial effect on dyspnoea cannot be ascribed to oxygen, since an equal efficacy was obtained with $10 \mathrm{mg}$ nebulized morphine, without the addition of oxygen. Our results suggest rather a placebo effect and/or a nonspecific effect, possibly mediated through a decrease in respiratory frequency. A placebo effect of similar magnitude on dyspnoea 
at rest has been demonstrated previously following nebulized saline in patients with severe asthma or COPD [7]. Other studies have provided arguments in favour of a nonspecific reduction in dyspnoea related to the use of either nasal prongs [18], or a face mask [21].

In conclusion, we have shown that 10 or $20 \mathrm{mg}$ nebulized morphine, administered via a mouthpiece, combined with oxygen via nasal prongs, is not more effective than isotonic saline in relieving disabling dyspnoea in patients with advanced disease. This result is not unexpected, in view of several studies that have reported a lack of effect of nebulized morphine on exercise-induced dyspnoea in various populations [14-17], but is at variance with the description of a beneficial effect from inhaled opioids on dyspnoea at rest in a recent uncontrolled study [4]. Our patients benefited symptomatically from either saline or morphine, as a result of a placebo effect and/or a nonspecific effect from treatment. Our findings do not support the hypothesis that nebulized morphine, at a dose of 10 or $20 \mathrm{mg}$, has an intrapulmonary action of clinical relevance.

Acknowledgements: The authors thank F. Martinez Vadillo for secretarial assistance.

\section{References}

1. Johnson MA, Woodcock AA, Geddes DM. Dihydrocodeine for breathlessness in "pink puffers". Br Med J 1983; 286: 675-677.

2. Light RW, Muro JR, Sato RI, et al. Effects of oral morphine on breathlessness and exercise tolerance in patients with chronic obstructive pulmonary disease. Am Rev Respir Dis 1989; 139: 126-133.

3. Tooms A, McKenzie A, Grey H. Nebulised morphine. Lancet 1993; 342: 1123-1124.

4. Farncombe M, Chater S, Gillin A. The use of nebulized opioids for breathlessness: a chart review. Palliat Med 1994; 8: 306-312.

5. Bostwick DG, Null WE, Holmes S, et al. Expression of opioid peptides in tumors. $N$ Engl J Med 1987; 317: 1439-1443.

6. Folstein MF, Folstein S, McHugh PR. "Mini-mental state": a practical method for grading the cognitive state of patients for the clinician. J Psychiatr Res 1975; 12 : 189-198.

7. Noseda A, Schmerber J, Prigogine T, Yernault JC. Perceived effect on shortness of breath of an acute inhalation of saline or terbutaline: variability and sensitivity of a visual analogue scale in patients with asthma or COPD. Eur Respir J 1992; 5: 1043-1053.

8. Young IH, Daviskas E, Keena VA. Effect of low-dose nebulised morphine on exercise endurance in patients with chronic lung disease. Thorax 1989; 44: 387-390.

9. MacLeod RD, King BJ. Relieving breathlessness with nebulized morphine. Palliat Med 1995; 9: 169.

10. Davis CL. The use of nebulized opioids for breathlessness. Palliat Med 1995; 9: 169-170.

11. Chrubasik J, Wust H, Friedrich G, Geller E. Absorption and bioavailability of nebulized morphine. Br J Anaesth 1988; 61: 228-230.

12. Noseda A, Schmerber J, Prigogrne T, Yernault JC. How do patients with either asthma or COPD perceive acute bronchodilation? Eur Respir J 1993; 6: 636-644.

13. Noseda A, Schmerber J, Prigogine T, de Maertelaer V, Yernault JC. Perception of dyspnoea during acute changes in lung function in patients with either asthma or COPD. Respir Med 1995; 89: 477-485.

14. Beauford W, Saylor TT, Stansbury DW, Avalos K, Light RW. Effects of nebulized morphine sulfate on the exercise tolerance of the ventilatory limited COPD patient. Chest 1993; 104: 175-178.

15. Masood AR, Subhan MMF, Reed JW, Thomas SHL. Effects of inhaled nebulized morphine on ventilation and breathlessness during exercise in healthy men. Clin Sci 1995; 88: 447-452.

16. Masood AR, Reed JW, Thomas SHL. Lack of effect of inhaled morphine on exercise-induced breathlessness in chronic obstructive pulmonary disease. Thorax 1995; 50: 629-634.

17. Harris-Eze AO, Sridhar G, Clemens E, et al. Low-dose nebulized morphine does not improve exercise in interstitial lung disease. Am J Respir Crit Care Med 1995; 152: 1940-1945.

18. Liss HP, Grant BJB. The effect of nasal flow on breathlessness in patients with chronic obstructive pulmonary disease. Am Rev Respir Dis 1988; 137: 1285-1288.

19. Swinburn CR, Mould H, Stone TN, Corris PA, Gibson GJ. Symptomatic benefit of supplemental oxygen in hypoxemic patients with chronic lung disease. Am Rev Respir Dis 1991; 143: 913-915.

20. Bruera E, de Stoutz N, Velasco-Leiva A, Schoeller T, Hanson J. Effects of oxygen on dyspnoea in hypoxaemic-terminal cancer patients. Lancet 1993; 342: 13 14.

21. Schwartzstein RM, Lahive K, Pope A, Weinberger SE, Weiss JW. Cold facial stimulation reduces breathlessness induced in normal subjects. Am Rev Respir Dis 1987; 136: 58-61. 